\title{
Ativismo, políticas públicas e acesso a medicamentos: o uso de oposiçóes a pedidos de patentes por organizaçóes da sociedade civil
}

| 1 Pedro Villardi I

Resumo: O artigo aborda o problema do acesso aos medicamentos ARVs e a construção da agenda de lutas do movimento social da AIDS, especificamente o caso do tenofovir, suas pró-drogas e a combinação com a emtricitabina. Discute de que estratégias o movimento AIDS lançou mão para evitar que tais medicamentos fossem patenteados, utilizando o método monográfico e a posição de insider do autor para fazer a análise.

> Palavras-chave: acesso a medicamentos; movimento social da AIDS; tenofovir; patentes; oposição a patentes.
1 Doutorando, bolsista PROEX/ CAPES. Instituto de Medicina Social, Universidade do Estado do Rio de Janeiro. Rio de Janeiro-RJ, Brasil (pvillardi@gmail.com). ORCID: 0000-0001-7788-6055

Recebido em: 02/09/2017 Aprovado em: 21/02/2018 Revisado em: 28/02/2018 


\section{Introdução}

Neste artigo, trataremos do problema do acesso a tecnologias essenciais para a garantia do direito à saúde, os medicamentos ARVs e a construção da agenda de lutas do movimento social da AIDS, em especial, do Grupo de Trabalho sobre Propriedade Intelectual (GTPI). ${ }^{1}$ Especificamente, abordaremos o caso do tenofovir, suas pródrogas e a combinação com a emtricitabina (o Truvada ${ }^{\circ}$ e as estratégias que o movimento AIDS lançou mão para evitar que tais medicamentos fossem patenteados.

Para fazer tais análises, este artigo usará de método monográfico, a partir de premissas consagradas da antropologia cultural, que se apoia na posição do autor como insider (AMARAL, 2009; ROSA, OREY, 2012); no caso presente, nas experiências, vivências e no conhecimento adquirido pelo autor por meio de quase uma década de trabalho no GTPI. Além disso, também nos apoiaremos em análises bibliográficas e documentais. Portanto, este trabalho está constituído a partir da ação política e da pesquisa que daí resultou e de leitura crítica de pesquisa bibliográfica e documental.

Para fins de apresentação, o artigo está organizado da seguinte maneira. $\mathrm{Na}$ primeira seção, tratamos da entrada do patenteamento farmacêutico na agenda do movimento social de AIDS; ou seja, de que maneira regras de propriedade intelectual passaram a ser trabalhadas pelo movimento AIDS. Em seguida, discutimos os efeitos das patentes sobre as políticas de acesso universal e ARVs. E, em uma terceira parte, é feita uma apresentação de casos - do TDF, TAF e TDF+FTC -, de forma a trazer a reflexão sobre a questáo do uso do dispositivo legal de oposiçôes a patentes por parte de organizaçôes da sociedade civil.

\section{Ativismo e políticas públicas: os medicamentos na agenda do movimento social de AIDS}

Foi logo no início da epidemia de AIDS, em meados da década de 1980, que os medicamentos entraram na agenda do movimento social da AIDS. Pode-se afirmar que nos primeiros anos da epidemia, de modo geral, os tipos de organizaçôes de ativistas podiam ser identificados quanto à natureza de seu trabalho e em relaçáo aos objetivos pleiteados em sua prática associativista e em sua agenda de lutas.

$\mathrm{O}$ primeiro tipo se dedicava ao acolhimento e ao cuidado à pessoa vivendo com HIV/AIDS, como as casas de apoio ou de passagem e abrigos, ou ainda - em um momento posterior - organizaçôes que ofereciam apoio psicológico, terapias 
complementares etc. O segundo tipo eram as organizaçóes que focavam seu trabalho em disputar o desenho e a execução de políticas de prevenção e tratamento, defesa dos direitos humanos e luta por benefícios sociais, como aposentadoria, vale-transporte, cestas básicas, entre outros. Dentro das organizações que trabalhavam nesta última perspectiva, encontrava-se aquelas que, desde a origem, miravam na questão da adesão aos tratamentos e em formas de garantir sua continuidade com antirretrovirais e nas coinfecçóes, como tuberculose e hepatite (CERQUEIRA; TERTO JR., 2015).

$\mathrm{O}$ ativismo ligado à questão do acesso aos medicamentos inaugura-se no final da década de 1980, quando surgiram os primeiros medicamentos que mostravam eficácia no controle do vírus HIV no sangue e que ficaram conhecidos como altamente ativos contra a AIDS (HAART, sigla em inglês), trazendo esperança para as pessoas soropositivas.

Inicialmente, não havia estudos que demonstrassem que o uso combinado dos medicamentos - sendo os dois primeiros, azt e ddi - fosse mais eficaz que seu uso isolado; uso isolado que, como observado na prática médica, acabava rapidamente se tornando sem efeito. Assim, grupos de pacientes vivendo no Norte global e, um pouco mais tarde, aqueles dos países em desenvolvimento, como o Brasil, pressionavam a indústria e centros de pesquisa para desenvolverem mais e melhores medicamentos (EPSTEIN, 1996).

A partir do final da década de 1980, começam a surgir no Brasil as primeiras ONGs que incluíam em sua missão a democratização da informação sobre os medicamentos, como: Pela Vidda/SP, ABIA, no Rio de Janeiro, e Pela Vidda/RJ. A ONG Pela Vidda/SP lançou, ainda em 1989, a publicação Cadernos Pela Vidda, organizada pelo ativista Jacques Bouchara. A publicação buscava trazer de forma simples e direta informaçôes complexas e até então distantes sobre os medicamentos: quais eram seus efeitos sobre o vírus, os efeitos adversos no corpo de portadores e doentes, bem como o monitoramento de informaçóes sobre ensaios clínicos e possíveis lançamentos de novos medicamentos. Logo, outras organizaçóes passaram também a lançar publicaçôes sobre o tema (CERQUEIRA; TERTO JR., 2015).

No campo da saúde, militantes da Reforma Sanitária, entre os quais se encontravam ativistas da luta contra a AIDS, pressionavam por um sistema de saúde baseado em princípios como integralidade, universalidade e participação social. A partir do quadro institucional da Constituição de 1988, a Constituição-cidadã, que 
colocava a saúde como direito de todos e dever do Estado e a participaçáo social como fundamento da política de saúde, a luta contra a AIDS ganha novos contornos.

Em relação à resposta governamental, em 1985 o governo federal brasileiro criou o Programa Nacional de Doenças Sexualmente Transmissíveis e Aids (PN-DST/ Aids), com açôes que iam da prevenção ao tratamento de doenças oportunistas. Desde as primeiras açóes contra a epidemia, governo e sociedade civil sempre interagiram na elaboração de estratégias (CERQUEIRA; TERTO JR., 2017). Essa é uma marca constitutiva do campo social da AIDS: a chamada intersetorialidade.

A intersetorialidade é resultado justamente da entrada das organizaçôes da sociedade civil organizada como agentes do debate com capacidade de gerar suas próprias evidências, o que lhes permitia entrar nas discussóes e nos espaços formais de participação em condições de igualdade. Assim, de forma colaborativa e conflitiva, interagem no campo social da AIDS o poder público, a comunidade científica e o movimento social. No entanto, a participação do movimento social nos debates só teria sentido a partir de comunidades mobilizadas.

Para mobilizar, era preciso informação acessível. As organizaçóes, portanto, tinham de se dedicar a "traduzir" as informaçôes técnicas sobre medicamentos, ensaios clínicos e pesquisas promissoras para uma linguagem democrática e mobilizadora. Em publicaçôes ou em debates, os ativistas falavam a partir da vivência da doença, o que gerava as evidências que embasavam o posicionamento crítico das organizaçóes na economia política da epidemia e permitiu traduzir o conhecimento científico, democratizando a informação (VILLELA, 2015).

No entanto, quando os novos medicamentos antirretrovirais começam a surgir, o debate do qual participavam as organizaçóes do campo social se complexificou. Para superar a complexidade do tema, organizaçóes como a ABIA e o Pela Vidda/ SP passaram a incluir em suas publicaçôes informaçôes sobre os novos tratamentos. Em pouco tempo, a demanda do fornecimento de ARVs passou a ser uma das bandeiras mais importantes do movimento AIDS (VILLELA, 2015; CERQUEIRA; TERTO JR., 2017).

Do ponto de vista da resposta brasileira à epidemia, a distribuição de medicamentos foi um dos aspectos de maior destaque. Para suprir as necessidades de saúde publica na área, o Estado brasileiro investiu na produção local de medicamentos antirretrovirais já lançados no mercado internacional, copiando-os, via engenharia reversa (CASSIER; CORREA, 2012). Os sete primeiros ARVs distribuídos pelo governo brasileiro - 
zidovudina, didanosina, zalcitabina, lamivudina, estavudina, indinavir e nevirapina eram todos produzidos nacionalmente nos laboratórios públicos e privados, liderados por Farmanguinhos (CASSIER; CORREA, 2003; TEIXEIRA, 2003).

Até 1997, o Brasil não concedia patentes farmacêuticas, o que tornava a cópia legal e permitia que medicamentos vendidos a preços exorbitantes nos países do Norte global fossem produzidos a baixo custo. Foi a capacidade de produçáo local de medicamentos (a baixo custo) o que permitiu ao governo brasileiro oferecer tratamento para as pessoas com AIDS no Brasil (CHAVES et al., 2008), aspecto fundamental para a dimensão da integralidade, preconizada pelo Movimento Sanitário, defendida pelas ONGs AIDS e entronizada na lei orgânica da saúde, desde a criação do SUS (CERQUEIRA; TERTO JR., 2015).

Como longamente estudado por Cassier e Correa (2007; 2012), refletir sobre a imbricação entre políticas de saúde pública, conhecimentos científicos e tecnológicos e inciativas industriais de produção farmacêutica local é fundamental para a compreensão da construção da agenda de acesso a medicamentos do movimento social de AIDS. A partir de meados da década de 1990, um novo aspecto é incorporado à agenda de acesso a medicamentos, modificando-a radicalmente.

\section{Mudança no regime de propriedade intelectual: patentes na agenda do movimento social de AIDS}

A partir de 1994, um novo elemento passaria a ocupar a atenção de algumas organizaçóes: o Acordo Trips. Assinado como um dos acordos fundadores da Organização Mundial do Comércio (OMC), o Acordo Trips harmonizava os padrôes de propriedade intelectual no mundo, fixando um mínimo obrigatório para todos os países signatários da OMC. Esse Acordo estabeleceu a obrigatoriedade de todos os países signatários reconhecerem patentes para todos os campos tecnológicos, incluindo o farmacêutico. Como todos os outros países que aderiram à OMC, o Brasil teve de mudar sua lei de propriedade intelectual, passando a permitir o patenteamento de medicamentos.

Logo a seguir, em 1996, três marcos, a princípio aparentemente não associados, alteram de forma significativa a dinâmica social no campo da AIDS, no Brasil. O primeiro, cujos reflexos são globais, foi o anúncio, na IX Conferência de AIDS, em Vancouver, da eficácia da terapia combinada, a chamada terapia tríplice, que ficou 
popularmente conhecida como "coquetel". A comunidade científica provara que a combinação de três medicamentos era eficaz e não gerava resistências ao vírus no curto prazo. O segundo, o compromisso assumido pelo Estado brasileiro, por meio da Lei no 9.313, a chamada Lei Sarney, de garantir acesso universal e gratuito aos medicamentos antirretrovirais. A terceira, a aprovação da Lei no 9.279, a chamada Lei de Patentes, que alteraria o status dos medicamentos no Brasil, transformandoos em bens passíveis de serem patenteados. O resultado prático é que a cópia de medicamentos, até então alicerce da política de distribuição de medicamentos, se tornaria ilícita, caso os novos ARVs tivessem patentes concedidas no Brasil.

O terceiro marco, a aprovação da Lei de Patentes, não se tornou um tema para as organizaçóes do movimento social de luta contra a AIDS imediatamente, tendo o debate ficado restrito a sindicatos, organizaçōes de classe e o setor privado (REIS, 2015). Segundo Villela (2015), inicialmente, a questão da propriedade intelectual só aparecia nos debates quando se tratava de casos de desabastecimento.

Com o passar dos anos, no entanto, o entendimento de que os novos medicamentos, agora patenteados também no Brasil, poderiam ameaçar a sustentabilidade do Programa Nacional de DST/AIDS ganhou força no movimento social (CHAVES et al., 2008; VILLELA, 2015). De maneira heterogênea, os meandros técnicos foram sendo destrinchados pelos ativistas ao redor do mundo.

Inicialmente, organizaçóes internacionais, como Médicos sem Fronteiras (MSF) e Oxfam, tomaram para si o papel de articuladoras da agenda em nível nacional, uma vez que as organizaçôes brasileiras pareciam reticentes a entrar no debate. Um dos motivos apontados era o entendimento das organizaçóes - muito inspiradas no posicionamento do Movimento Sanitário - de que os aspectos técnicos da saúde pública deveriam ser responsabilidade do Estado e que organizaçóes da sociedade civil deveriam se dedicar a pressionar o poder público a formular políticas, de modo a cumprir seu dever constitucional (VILLELA, 2015). No entanto, essa postura se modificou rapidamente.

Um dos motivos apontados por Villela (2015) é o Processo de Pretória. Em 1998, em meio a uma epidemia descontrolada na África do Sul e com companhias farmacêuticas cobrando preços altíssimos pelos medicamentos ARVs, o então presidente da África do Sul, Nelson Mandela, busca incluir na lei sul-africana dispositivos que permitissem ao país a importação de medicamentos genéricos a preços mais acessíveis. Em resposta a essa tentativa, dezenas de laboratórios 
farmacêuticos transnacionais processam Nelson Mandela, pedindo sua prisão por violar seus direitos de patentes.

Em 2001, após grande pressão de organizaçôes da sociedade civil de diversos países, destacadamente da Europa, as farmacêuticas abandonam o caso (MSF, 1998). Em São Paulo, organizaçôes brasileiras somaram-se à pressão e ativistas brasileiros protestaram em frente ao consulado estadunidense, demandando que a saúde tivesse preponderância sobre os direitos de propriedade intelectual. Nesse mesmo ano, a Declaração de Doha sobre Trips e Saúde Pública, emitida pela própria OMC, também dá visibilidade ao tema, atraindo atençáo e convencendo organizaçóes da sociedade civil organizada do Brasil de que o tema das patentes e seu impacto na saúde pública deveria ser trabalhado de forma estruturada nacionalmente (CHAVES et al., 2008).

Nacionalmente, o trabalho na interface entre patentes e saúde pública tomou corpo quando da criação, ainda em 2001, do Grupo de Trabalho sobre Propriedade Intelectual (GTPI), no âmbito da Rede Brasileira pela Integração dos Povos (Rebrip). ${ }^{2}$ A Rebrip é uma rede de organizaçóes e movimentos sociais que nasce com o objetivo de lutar contra o neoliberalismo e os tratados de livre comércio. Trata-se, essencialmente, de um espaço de articulação que congrega desde a Central Única dos Trabalhadores (CUT) à MSF, passando por ONGs nacionais e outras organizaçóes sindicais menores.

Ao contrário dos outros grupos de trabalho da Rebrip, que tinham agenda quase que predominantemente internacional, o GTPI construiu sua agenda calcada nas demandas nacionais. O principal motivo apontado é a própria composição do GTPI quando de sua criação: majoritariamente ONGs do campo da AIDS, que levaram para o GTPI a preocupação com a integralidade de atenção e com a sustentabilidade do programa de acesso universal (VILLELA, 2015).

Na gênese do GTPI está, portanto, uma concepçáo de saúde gestada no Movimento Sanitarista dos anos 1970, e que via no Programa Nacional de AIDS e na distribuição universal de medicamentos "o SUS levado às últimas consequências" (SCHEFFER, 2012). O posicionamento do GTPI, sobre a tensão patentes-acesso universal, portanto, articulava de maneira complexa a incorporação de novos medicamentos. Por um lado, era importante incorporar os novos medicamentos, uma vez que trariam benefícios para as pessoas vivendo com HIV/AIDS, como mais qualidade de vida e menos efeitos adversos, e o fortalecimento do SUS. Por outro, 
era preciso lidar com a pressão orçamentária que esses medicamentos exerceriam, por ser medicamentos sob monopólio.

Para o grupo, a resposta estava na luta contra patentes que permitiam às empresas farmacêuticas cobrar altos preços pelos medicamentos a serem incorporados. Vejamos a seguir como tais aspectos se articulam no caso tenofovir.

\section{A luta para colocar medicamentos em domínio público: o caso tenofovir}

Desde sua criação, o GTPI se dedica a criar estratégias para impedir que patentes farmacêuticas ameacem a sustentabilidade das políticas de acesso a medicamentos e, em última instância, o próprio direito à saúde. Com isso, o coletivo desenvolveu estratégias para atacar os monopólios que permitem aos laboratórios cobrar altos preços. Em outras palavras, o GTPI busca recolocar os medicamentos em domínio público ou, antes disso, impedir que venham a ser patenteados, de maneira que versôes genéricas desses medicamentos possam chegar ao mercado, o que coloca opçóes de compra para os governos (VILLELA, 2015).

A preocupação com o tema das patentes de medicamentos e seus reflexos na sustentabilidade do Programa Nacional se confirmou. Entre o final dos anos 1990 e meados dos anos 2000, o Brasil incorporou novos medicamentos ao rol das terapias distribuídas pelo Programa Nacional. As incorporações de medicamentos patenteados e o incremento do número de pacientes e portadores do HIV, usuários de antirretrovirais, aumentaram significativamente os recursos gastos pelo governo brasileiro com a compra de medicamentos (CHAVES et al., 2008).

O Estado brasileiro adotava, portanto, políticas públicas com perspectivas paradoxais: na área da saúde, comprometera-se a oferecer terapias anti-HIV/ AIDS de forma universal e gratuita, e, contraditoriamente, na área da propriedade industrial, tornava as tecnologias químico-farmacêuticas passíveis de monopólios, o que acarretaria preços altos para a aquisição de medicamentos. Havia, portanto, um cenário de tensão.

Em 2005, o governo brasileiro declara que a política de acesso a medicamentos estava em risco, devido ao alto custo das novas drogas, agora patenteadas (GRANGEIRO et al., 2006). Nesse ano, três medicamentos consumiram quase $80 \%$ dos recursos do então PN-AIDS sendo um deles o tenofovir. 
O tenofovir é um inibidor nucleotídeo da transcriptase reversa (ITRN) aprovado, primeiramente, pela agencia norte-americana Food and Drug Administration (FDA), em 26 de outubro de 2001, para o tratamento de infecçóes causadas pelo HIV e para hepatite B crônica. O Viread ${ }^{\circledR}$, nome comercial do fumarato de tenofovir desoproxila (TDF), é uma pro-droga do tenofovir (CHUNG et al., 2005). Em 2006, o TDF logo passou a ser oferecido como opção preferencial para primeira linha de tratamento contra o HIV/AIDS. À época, cerca de $20 \mathrm{mil}$, das $170 \mathrm{mil}$ pessoas em tratamento, tomavam TDF (ABIA et al., 2006).

O fato de o número de pessoas em tratamento crescer progressivamente, utilizando medicamentos adquiridos pelo governo a preços altos, passou a ser uma ameaça à continuidade da política de acesso universal. Face a essa ameaça, o GTPI buscou no ativismo político e dentro da institucionalidade caminhos para diminuir o preço do tenofovir.

\section{O uso de oposiçóes a patentes por organizaçóes da sociedade civil}

Como mencionado, o GTPI tem como missão mitigar o efeito das patentes sobre políticas de acesso a medicamentos. Uma das formas vislumbradas pelo grupo foi pressionar o poder público para que fizesse uso de uma das salvaguardas do Trips conhecida como licença compulsória, e midiaticamente denominada como "quebra de patentes”. A emissão da licença compulsória permite que outros laboratórios, públicos e privados, passem a produzir e comercializar o medicamento até então patenteado (ABIA, 2005; VILLELA, 2015).

Em 2005, o GTPI passa a ser coordenado pela advogada Renata Reis, o que marca uma inflexão nas estratégias do coletivo. Por sua experiência com propriedade intelectual, Reis faz com que o coletivo se aproprie de maneira profunda dos meandros jurídicos do tema. Uma das atividades mais importantes foi a busca de patentes dos medicamentos relevantes para o movimento social de AIDS e aqueles que consumiam parcela relevante do orçamento do programa público de acesso universal (VILLELA, 2015).

Já nos primeiros anos após a incorporação do tenofovir, o governo brasileiro empenhava grande volume de recursos para aquisição desse e de outros medicamentos importados, mesmo sem que os medicamentos tivessem patentes concedidas no 
Brasil. Em outras palavras, a Gilead, empresa americana que comercializada o tenofovir no Brasil sob a marca Viread ${ }^{\oplus}$, gozava de monopólio de facto, enquanto o pedido de patente depositado no Instituto Nacional da Propriedade Industrial (INPI) era analisado; ou seja, enquanto estava ainda pendente.

Nos casos em que ainda não há decisão final sobre a patente, a lei brasileira prevê um mecanismo em nível administrativo, do Instituto Nacional da Propriedade Industrial (INPI), chamado subsídio ao exame (BRASIL, 1996). Esse mecanismo, previsto no art. 31 da Lei de Patentes brasileira, permite a terceiros interessados apresentarem argumentos técnicos, que servirão de subsídio para o parecer final do examinador de patentes. Pelo fato de, usualmente, os argumentos serem contrários à concessão da patente, o subsídio também é conhecido como oposição à patente.

O subsídio ao exame já era utilizado por empresas, que buscavam impedir uma reserva de mercado (ABRANTES, 2014; STEUER, 2014). Em 2005, no entanto, o uso desse mecanismo pelo setor público - nesse caso, pelo laboratório farmacêutico Farmanguinhos da Fundação Oswaldo Cruz, ligada ao Ministério da Saúde, abre uma nova fronteira no sentido de protocolar oposições no Brasil e em outros países do Sul Global (BARROSO, 2010).

No mesmo ano de 2005, quando Farmanguinhos protocolava uma monografia de oposição ao pedido de uma das patentes do tenofovir (PI9811045-4) depositadas no INPI, ativistas indianos lutavam para impedir que a molécula fosse patenteada na Índia. Os argumentos técnicos usados na oposiçấo depositada pelo laboratório público brasileiro junto ao INPI validaram a oposição que vinha sendo desenvolvida e que favoreceu que se protocolasse uma oposiçáo à patente da Gilead na Índia. A estratégia utilizada por ativistas indianos, por sua vez, chegou ao GTPI, que, com base nos argumentos da oposição indiana e da de Farmanguinhos, elabora sua própria oposição. No documento, o GTPI apontou que o pedido de patente da farmacêutica Gilead não cumpria com os requisitos de novidade e atividade inventiva (ABIA et al., 2006).

Para que uma patente seja concedida, o pedido tem de cumprir com os chamados requisitos de patenteabilidade: (a) novidade, (b) atividade inventiva; (c) aplicação industrial. Estes três requisitos foram fixados como obrigatórios pelo Acordo Trips. Porém, há diversas formas de interpretar tais requisitos (CORREA, 2000), e o texto do Acordo deixou aberta aos países signatários do Acordo a definição de como tais requisitos seriam incorporados à lei nacional. Do ponto de vista da saúde pública, é 
fundamental que os requisitos de patenteabilidade sejam interpretados da maneira mais rígida possível para que menos patentes sejam concedidas (HLPAM, 2016).

O uso desse mecanismo por associações e ONGs do movimento social no Brasil pode ser considerado uma inovação sob dois ângulos. $\mathrm{O}$ primeiro, devido à natureza não empresarial do grupo; e o segundo, pelo desinteresse por aspectos comerciais no produto. O objetivo do GTPI ao protocolar a oposição era impedir que um medicamento importante para o tratamento do HIV/AIDS fosse patenteado, o que manteria seu custo alto, ou seja, em vez de um uso para disputar o mercado, trata-se de um uso para desmercantilizar o medicamento.

O subsídio ao exame jamais havia sido utilizado por nenhum grupo da sociedade civil, no Brasil. A composição do grupo e seu desinteresse pela exploração da tecnologia ensejaram, inclusive, que as páginas iniciais da oposição, de forma extensa, trouxessem uma defesa do interesse e dos motivos que as organizaçóes que assinaram o documento (ABIA, Conectas DH, Grupo Pela Vidda/SP, GAPA/SP, GAPA/RS, GESTOS e GIV) tinham para apresentação de documento daquela natureza. A apresentação da oposição do INPI ainda foi carregada de simbolismo, pois foi feita no dia $1^{\circ}$ de dezembro de 2006, o dia mundial de luta contra a AIDS. ${ }^{3}$

A experiência do uso da oposição à patente por um coletivo de organizaçooes da sociedade civil articula eixos importantes que compóem a essência do GTPI em uma nova forma de fazer ativismo: (a) a herança do movimento sanitarista, buscando o fim do monopólio sobre produtos e serviços de saúde com vistas a garantir a integralidade e a universalidade das políticas de saúde; (b) o potencial pedagógico das intervenções políticas do GTPI, exercendo a vocação para democratizar e politizar o conhecimento técnico e transformar a linguagem científica em linguagem mobilizadora; ao mesmo tempo, invadindo a arena institucional restrita ao poder público, ao setor privado e aos escritórios de advocacia; (c) construção da agenda política a partir da vivência das pessoas com HIV, na medida em que, tendo em sua composição diversos ativistas que vivem com HIV, a decisão sobre para que medicamento se deva fazer a oposição parte da vivência da epidemia. Esses três elementos trazem um novo significado ao instrumento legal do subsidio ao exame e ao ato de interpor oposiçóes de patentes no INPI.

A oposição à patente do tenofovir foi a primeira apresentada pelo GTPI, em 2006. Nos anos que se seguiram, outras oposiçôes foram protocoladas, inclusive para outras patentes depositadas, também para o tenofovir. 


\section{A segunda oposição à patente do tenofovir, a combinação TDF+FTC e o TAF}

Em agosto de 2008, menos de dois anos de a oposição do GTPI ter sido protocolada, o INPI negou a concessão da patente ao pedido PI9811045-4. Embora consideremos um passo importante, essa decisão não foi suficiente para colocar o tenofovir em domínio público, em função da existência de outros pedidos de patentes ${ }^{4}$ depositados pela farmacêutica Gilead cobrindo a mesma molécula. Em função da estratégia de depósito de um grande número de diferentes pedidos de patente para o mesmo produto, tenofovir, o indeferimento da concessão de patente a um desses pedidos, o pedido PI9811045-4 relativo ao tenofovir, não foi suficiente para permitir ao governo brasileiro comprar ou produzir localmente versóes mais baratas do medicamento.

Assim, a partir de 2007, com o crescimento do número de pessoas utilizando regimes baseados em tenofovir, o medicamento era o que mais consumia recursos do programa brasileiro de AIDS (ABIA et al., 2009). Com o objetivo de colocar o tenofovir em domínio público, o GTPI, em novembro de 2009, entrou com nova oposição à patente, dessa vez, em referência ao pedido de número PI9816239-0.

Essa segunda oposição traz duas novidades em relação à primeira protocolada para o tenofovir. Uma diferença diz respeito à natureza das argumentaçóes apresentadas: enquanto a primeira oposição trazia argumentos que se restringiam ao campo químico-farmacêutico, a oposição apresentada em 2009 incluiu argumentos jurídicos. O GTPI defendeu que era ilegal a inclusão de nova matéria em pedido de patente divisional ${ }^{5}$ (ABIA et al., 2009).

Outra diferença está no nível de colaboração com organizaçôes da Índia. Enquanto na oposição apresentada em 2006 houve apenas colaboração entre organizaçôes indianas e brasileiras, a oposição apresentada em 2009 traz um feito inédito: o GTPI e a organização Sahara Centre for Residential Care and Rehabilitation protocolaram oposiçôes no Brasil e na Índia no mesmo dia, em um gesto de cooperação Sul-Sul entre organizações da sociedade civil.

A exemplo da oposição protocolada em 2006, a de 2009 também foi bem-sucedida: o pedido de patente foi negado. Com isso, as patentes que poderiam bloquear a produção e a comercialização do tenofovir no Brasil estavam negadas: o tenofovir estava em domínio público. Havia, no entanto, outras questóes para o GTPI. 
Em 2010, outro pedido envolvendo o tenofovir foi identificado, o PI04067606. Dessa vez, o pedido referia-se à combinação de dois medicamentos, o TDF e a emtricitabina (FTC), de nome comercial Truvada. A combinação em dose fixa traz a diminuição do número de comprimidos a serem tomados por dia, auxiliando o paciente a manter a adesão ao tratamento. Além disso, o Truvada ${ }^{\circledR}$ trazia um componente singular, que aparecia, inclusive, em algumas reivindicaçóes das organizaçôes de luta contra a AIDS e acesso a medicamentos: a atividade na prevenção ao HIV.

Mais uma vez, tomando como norte a evidência gerada a partir da experiência das pessoas vivendo com HIV e dos ativistas do coletivo para construir a agenda de lutas do movimento, o GTPI parte para elaborar mais uma oposição: dessa vez, para a combinação de medicamentos tdf $+\mathrm{ftc}$. A partir do levantamento do status patentário da emtricitabina, verificou-se que o medicamento não tinha patentes concedidas ou pendentes no Brasil (VILLARDI, 2012).

Tratava-se, portanto, da tentativa de patentear uma combinação de dois medicamentos ARVs, ambos em domínio público no Brasil. Ainda mais grave, havia o risco de o próprio tdf ser retirado de domínio público, mesmo após grande esforço do GTPI para impedir seu patenteamento.

O GTPI apresenta, então, no dia $1^{\circ}$ de dezembro de 2010, mais uma oposição, assinada por diversas organizaçóes do coletivo, a exemplo das anteriores, para impedir o patenteamento da combinação tdf+ftc (PI0406760-6). O GTPI defendeu, nesse caso, que não se poderia patentear uma combinação de dois medicamentos que estavam em domínio público, uma vez que o requisito de novidade não seria atendido. Além disso, o coletivo ainda argumentou, com base na interpretação dos requisitos de patenteabilidade à luz da saúde pública (CORREA, 2000), que a combinação de dois medicamentos era um procedimento óbvio para um técnico no assunto, não atendendo, portanto, ao requisito de atividade inventiva, legalmente exigido para que a patente seja concedida.

O pedido PI0406760-6, conforme mudança de fluxo do exame de patentes no Brasil, após a Portaria Interministerial no $1.065 / 2012,{ }^{6}$ foi encaminhado para a Agência Nacional de Vigilância Sanitária (Anvisa) conceder ou não prévia anuência a esse pedido de patente. A Anvisa negou a anuência, porém foi obrigada a reverter a decisão, em função de recurso judicial interposto pela Gilead. 
O processo seguiu seu fluxo para o INPI, que adotou o parecer técnico já proferido pela Anvisa e, igualmente, emitiu um parecer contrário à concessão da patente em agosto de 2016. Após o parecer, o GTPI protocolou um subsídio complementar, argumentando que o pedido não cumpria os requisitos de patenteabilidade (ABIA, 2016).

No final de 2016, a firma Gilead fez uma manifestação sobre o parecer desfavorável do INPI e, no início de 2017, a empresa farmacêutica Blanver submeteu outro subsídio ao mesmo pedido de patente. O processo ainda está pendente, aguardando decisão final do INPI.

Entre 2013 e 2015, foram publicados trabalhos científicos que demonstraram benefícios clínicos de uma nova pró-droga do tenofovir, o TAF, em relação ao fumarato desoproxila, o TDF. A forma alafenamida do fumarato de tenofovir (TAF) alcança níveis mais elevados nas células infectadas pelo HIV (SAX et al., 2013; MILLS et al., 2015). Além disso, a dose administrada de TAF é menor, o que leva a menores concentraçôes no plasma sanguíneo, nos tecidos e órgãos, como rins e ossos.

Do ponto de vista do desenvolvimento de melhorias nas terapias existentes, de modo a avançar nas formas de combater a epidemia de AIDS, novas formulaçóes e pró-drogas como o TAF (que, como dito, se mostrou superior ao TDF) são importantes. No entanto, do ponto de vista da patenteabilidade dessas tecnologias, é preciso tecer algumas consideraçôes.

Nessa oposição, foi argumentado que esse pedido de patente não cumpre os requisitos de patenteabilidade, por não apresentar atividade inventiva. No campo da política pública em propriedade intelectual e, principalmente, nos aspectos que impactam políticas de saúde, há um importante debate sobre como interpretar os requisitos de patenteabilidade.

Nas experiências de apresentação de oposiçôes para TDF (duas), TDF+FTC e TAF, vimos que, por meio do depósito de monografias de oposição junto ao INPI, o GTPI buscou avançar uma agenda política sobre a forma de se analisar patentes no Brasil. Como indicou Correa (2000), a experiência das Guias de Patenteabilidade da Argentina (MAKE MEDICINES AFFORDABLE, 2017; MINISTERIO DE SALUD et al., 2012) e as recomendaçóes do relatório do Painel de Alto Nível sobre Acesso a Medicamentos, convocado pelo Secretariado Geral da ONU (HLP, 2016), aplicar os requisitos legais de patenteabilidade à luz da saúde pública implica interpretá-los do modo o mais estrito/restritivo possível. Isso significa diminuir a 
força do monopólio sobre medicamentos e reafirmar a supremacia direito à saúde sobre o direito de propriedade na área farmacêutica.

O TAF é fruto de pequenas alterações na molécula do tenofovir, esta desenvolvida na década de 1980, em uma universidade na antiga Tchecoslováquia (VERAS, 2014). Portanto, argumentar que um pedido não deve ser concedido por se tratar de uma pró-droga de uma molécula já conhecida e em domínio público vai além do que está em jogo no pedido em si. O pedido de patente para o TAF ainda está pendente.

O recurso ao dispositivo do subsídio ao exame de patentes (ou oposição à patente), previsto na lei brasileira de propriedade intelectual, reflete o debate sobre o que pode ou não entrar em domínio privado e por quê. Não à toa, em todas as oposiçóes apresentadas pelo GTPI há uma seção expondo os argumentos de saúde pública - esclarecendo questáo de como patentes impactam o acesso à saúde - e por que o medicamento, objeto do pedido de patente alvo da oposição, é importante para a garantia do direito à saúde (GTPI, 2017).

\section{Consideraçóes finais}

Ao longo deste artigo, buscamos apresentar processos históricos e políticos que levaram o GTPI a se envolver em disputas em torno do patenteamento do tenofovir. Essa molécula, desenvolvida há três décadas na então Tchecoslováquia, tem sido objeto de açôes para o movimento social brasileiro, que luta para que patentes farmacêuticas não ameacem a universalidade e a integralidade do SUS.

Para que fosse possível debater o trabalho do GTPI na apresentação de monografias de oposição à patente, recuperamos historicamente de que maneira o tema dos medicamentos começou a ser trabalhado pelo movimento social de luta contra a AIDS, um processo que começa ainda nos anos 1980. Observamos como princípios que estavam na raiz da Reforma Sanitária estiveram presentes na constituição do movimento AIDS e como o ano de 1996 trouxe modificaçôes importantes na dinâmica do campo social da AIDS, com a introdução da terapia tríplice e a aprovação da obrigação legal do Estado brasileiro de fornecer tratamento universal e gratuito para as pessoas que necessitavam tratamento. Contrariamente, o mesmo ano assistiu à aprovação da nova lei de propriedade industrial.

A partir disso, após contextualizar a tensão que emergiu entre a obrigação estatal de fornecer medicamentos ARVs e o patenteamento dessas tecnologias em saúde, 
debatemos de que forma a propriedade intelectual passou a fazer parte dos debates e tornou-se arena de disputa para o movimento AIDS, que desde a criação do GTPI, em 2003, concentra no coletivo trabalho dessa natureza.

$\mathrm{Na}$ busca por impedir que patentes ameaçassem as políticas de acesso universal aos medicamentos ARVs, descrevemos o uso de apresentação de oposiçôes a pedidos de patentes no processo de exame do INPI como uma das estratégias utilizadas pelo GTPI para colocar medicamentos em domínio público. Por sua exemplaridade e importância no tratamento anti-HIV/AIDS, neste artigo, abordamos o caso do medicamento tenofovir.

Desde 2006, portanto, há mais de uma década, o GTPI desenvolve açóes para impedir o patenteamento da molécula do tenofovir, seja na forma de pró-drogas, seja na forma de combinação com a emtricitabina. Nesse intervalo de tempo, foram quatro oposiçóes e um documento de complementação técnica apresentados no processo de exame de patentes no INPI.

Um dos aspectos que destacamos ao longo do artigo foi que, durante o processo de elaboração e apresentação de oposiçôes a patentes, articulam-se eixos que compõem a essência do GTPI: a herança dos princípios do movimento sanitarista (universalidade e integralidade); a transformação da linguagem técnica em mensagem mobilizadora; a construção da agenda política baseada na vivência das pessoas com HIV.

Ainda, buscamos trazer uma reflexáo sobre de que maneira os argumentos de natureza técnica apresentados extrapolam o processo na esfera administrativa do INPI em relação a um medicamento específico e passam a ser vetores de uma luta política maior: quais serão os critérios para definir que medicamentos devem ser patenteados e quais não. Em outras palavras, os argumentos técnicos do GTPI, usando os canais institucionais do próprio sistema de patentes, o tencionam-no para afirmar: medicamentos náo devem ser patenteados. No entanto, como mostrado no caso tenofovir, todo empenho do GTPI esbarra na Farmacêutica Gilead, que não mede esforços para ter uma patente para o tenofovir concedida.

Finalmente, em que pese o êxito do GTPI em manter em domínio público o TDF, por meio de duas oposiçôes à patente (2006 e 2009), ainda é preciso acompanhar o desenrolar dos casos TDF+FTC e do caso TAF, pois se forem concedidas patentes para esses dois medicamentos, o acesso a importantes tecnologias de saúde e, em última instância, a universalidade e a integralidade da política de acesso universal brasileira podem estar novamente em risco. 


\section{Referências}

ASSOCIAÇÃO BRASILEIRA INTERDISCIPLINAR DE AIDS; CONECTAS DIREITOS HUMANOS; GRUPO PELA VIDDA-SP; GRUPO DE APOIO À PREVENÇÃO À AIDSSP; GRUPO DE APOIO À PREVENÇÃO À AIDS-RS; GESTOS; SOROPOSITIVIDADE E GÊNERO; GRUPO DE INCENTIVO À VIDA. Subsidio ao exame técnico do pedido de patente PI9811045-4 (tenofovir). Apresentado em: 1/12/2006. Disponível em: <http://deolhonaspatentes. org/wp-content/uploads/2016/02/Subs\%C3\%ADdio-Tenofovir.pdf>. 2006.

ASSOCIAÇÃO BRASILEIRA INTERDISCIPLINAR DE AIDS; CONECTAS DIREITOS HUMANOS; GRUPO DE APOIO À PREVENÇÃO À AIDS-SP; GRUPO DE APOIO À PREVENÇÃO À AIDS-RS; GESTOS; SOROPOSITIVIDADE E GÊNERO; GRUPO DE INCENTIVO À VIDA; INSTITUTO DE DEFESA DO CONSUMIDOR, REDE NACIONAL DE PESSOAS+/SLS-MA. Subsídio ao exame técnico do pedido de patente PI9816239-O (tenofovir, pedido divisional). Apresentado em: 5/11/2009. Disponível em: <http:// deolhonaspatentes.org/wp-content/uploads/2016/02/Subsidio-Divisional-Tenofovir.pdf>. 2009.

- Subsidio ao exame técnico do pedido de patente PI0406760-6 (combinação tenofovir+emtricitabina). Apresentado em: 20/8/2010. Disponível em: <http://deolhonaspatentes. org/wp-content/uploads/2016/02/Subs\%C3\%ADdio-Truvada1.pdf>. 2010.

ASSOCIAÇÃO BRASILEIRA INTERDISCIPLINAR DE AIDS - ABIA. Complementação do subsidio ao exame técnico referente ao pedido de patente de invenção PI0406760-6. Apresentado em: 1/11/2016. Disponível em: <http://deolhonaspatentes. org/wp-content/uploads/2016/11/ Subsi\%CC\%81dio-truvada-II_final.pdf>. 2016.

ASSOCIAÇÃO BRASILEIRA INTERDISCIPLINAR DE AIDS - ABIA; GRUPO DE INCENTIVO À VIDA - GIV; GRUPO DE RESISTENCIA ASA BRANCA - GRAB; REDE NACIONAL DE PESSOAS VIVENDO COM HIV/AIDS NÚCLEO SÃO LUÍS - RNP+/SLS; UNIVERSIDADES ALIADAS PARA O ACESSO A MEDICAMENTOS ESSENCIAIS - UAEM. Subsidio ao exame técnico do pedido de patente referente ao pedido de patente de invenção PI0112646-6 (TAF). Apresentado em: 13/4/2016. Disponível em: <http:// deolhonaspatentes. org/wp-content/uploads/2016/05/subsidio_TAF_final-1-1.pdf>. 2016.

ABIA. Boletim ABIA - Acesso a medicamentos: uma urgência para a América Latina e Caribe - n52, 2005. Disponível em: <http://abiaids.org.br/_img/media/AAA52.pdf>. Acesso em: 7 jan. 2017. ABRANTES, A. Notícias em Patentes: Subsidios ao exame de patenteNoticias em Patentes, 11 nov. 2014. Disponível em: <http://patentescomentarios.blogspot.com.br/2014/11/subsidios-aoexame-de-patente.html>. Acesso em: 28 ago. 2017

AMARAL, A. Autonetnografia e inserção online: o papel do pesquisador-insider nas práticas comunicacionais das subculturas da Web. Fronteiras - estudos midiáticos, v. 11, n. 1, p. 14-24, 2009. 
BARROSO, W. Contribuição ao estudo do subsídio ao exame de pedido de patente no Brasil. In: AIDS e Saúde Pública: contribuiçôes à reflexão sobre ama nova economia política do medicamento no Brasil. Rio de Janeiro: Ed. UERJ, 2010. p. 244.

BRASIL. Lei no 9.279. Regula direitos e obrigaçôes relativos à propriedade industrial. Brasília, maio de 1996. Disponível em: <http:/www.planalto.gov.br/ccivil_03/Leis/L9279.htm>.

CASSIER, M.; CORREA, M. Patents, innovation and public health: Brazilian public-sector laboratories' experience in copying AIDS drugs. Economics of Aids Aid and Access in Developing Countries. Paris: ANRS, p. 89-107, 2003.

CASSIER, M.; CORREA, M. Intellectual Property and Public Health: copying of HIV/ Aids drugs by Brazilian public and private pharmaceutical laboratories. RECIIS, v. 1, n. 1, 29 jun. 2007.

CASSIER, M.; CORRÊA, M. Éloge de la copie : le reverse engineering des antirétroviraux contre le VIH/sida dans les laboratoires pharmaceutiques brésiliens. Sciences sociales et santé, v. Vol. 27, n. 3, p. 77-103, 15 nov. 2012.

CERQUEIRA, O.; TERTO JR., V. Sobre a construção da agenda de acesso a tratamentos para o HIV/AIDS no movimento social de AIDS no Brasil. In: Prêmio GTPI Jacques Bouchara de produção acadêmica voltada para o ativismo. Prêmio GTPI. Rio de Janeiro: Associação Brasileira Interdisciplinar de AIDS (ABIA), 2015.

CHAVES, G.; VIEIRA, M.; REIS, R. Acesso a medicamentos e propriedade intelectual no Brasil: reflexóes e estratégias da sociedade civil. Sur - Revista Internacional de Direitos Humanos, v. 8, n. Junho de 2008, p. 171-193, 2008.

CHUNG, M.-C. et al. Latenciação e formas avançadas de transporte de fármacos. Revista Brasileira de Ciências Farmacêuticas, v. 41, p. 155-180, 2005.

CORREA, C. Integrating Public Health Concerns into Patent Legislation in Developing Countries. Geneva: South Centre, 2000.

EPSTEIN, S. Impure Science. Los Angeles: University of California Press, 1996.

GRANGEIRO, A. et al. Sustainability of Brazilian policy for access to antiretroviral drugs. Revista de Saúde Pública, v. 40, p. 60-69, abr. 2006.

GTPI. ONU reconhece a necessidade da anuência prévia da ANVISADe olho nas patentes GTPI, 2016. Disponível em: <http://deolhonaspatentes.org/onu-reconhece-a-necessidade-daanuencia-previa-da-anvisa/>. Acesso em: 30 ago. 2017

GTPI. Contestação de patentes, 2017. Disponível em: <http://deolhonaspatentes.org/acoes/ contestacao-patentes-2/>. Acesso em: 7 jan. 2017

HLPAM. Report of the United Nations Secretary-General's High Level Panel on Access to Medicines. Geneva, New York: United Nations Secretary General, 2016. 
MAKE MEDICINES AFFORDABLE. Guias de patentabilidad en Argentina - Una medida de salud pública, 2017. Disponível em: <http://makemedicinesaffordable.org/es/recursos/ buenas-practicas-de/guias-de-patentabilidad-en-argentina-una-medida-de-salud-publica/>. Acesso em: 7 jul. 2017.

MILLS, A. et al. Switching From a Tenofovir Disoproxil Fumarate (TDF)-Based Regimen to a Tenofovir Alafenamide (TAF)-Based Regimen: Data in Virologically Suppressed Adults Through 48 Weeks of Treatment. In: $8^{\text {a }}$ CONFERÊNCIA DA INTERNATIONAL AIDS SOCIETY. Vancouver, Canadá, 2015. Disponível em: <http://www.natap.org/2015/IAS/IAS_24.htm>. Acesso em: 13 jan. 2017

MINISTERIO DE SALUD; MINISTERIO DE INDUSTRIA; INSTITUTO NACIONALDE LA PROPIEDAD INDUSTRIAL. Resolución Conjunta 118/2012, $546 / 2012$ y 107/2012. Apruébanse las pautas para el examen de Patentabilidad de las solicitudes de Patentes sobre Invenciones Químico Farmacéuticas, 2012.

MSF. 1998: Big Pharma versus Nelson Mandela, 1998. Disponível em: <https://www.msfaccess. org/content/1998-big-pharma-versus-nelson-mandela>. Acesso em: 6 fev. 2017

REIS, R. Redes invisiveis: grupos de pressão na Câmara dos Deputados - o processo de aprovação da Lei de Propriedade Industrial brasileira. Tese de Doutorado-Rio de Janeiro: Universidade Federal do Rio de Janeiro, 2015.

ROSA, M.; OREY, D. C. O campo de pesquisa em etnomodelagem: as abordagens êmica, ética e dialética. Educação e Pesquisa, v. 38, p. 865-879, 2012.

SCHEFFER, M. Boletim ABIA 58 - "Com a palavra, Mário Scheffer: SUS, AIDS e controle social”, 2012. Disponível em: <http://abiaids.org.br/_img/media/boletimAbia_58.pdf>

STEUER, H. A oposição a pedidos de patente no INPI. Disponível em: <http://www.dannemann. com.br/dsbim/Biblioteca_Detalhe.aspx?\&ID=930\&pp=1\&pi=2>. Acesso em: 28 ago. 2017.

TEIXEIRA, P. R. Acesso universal a medicamentos para Aids: a experiência do Brasil. Divulgação em Saúde para Debate, n. n. 27, p. 50-57, Agosto 2003.

VERAS, J. Making Tenofovir Accessible In The Brazilian Public Health System: Patent Conflicts And Generic Production. Developing World Bioethics, v. 14, n. 2, p. 92-100, Agosto 2014.

VILLARDI, P. Panorama do status patentário e registro sanitário dos medicamentos ARVs no Brasil. Implicaçóes para o acesso e para a política industrial de saúde. Rio de Janeiro: Associação Brasileira Interdisciplinar de AIDS (ABIA), 2012.

VILLELA, P. Ativismo terapêutico e propriedade intelectual de medicamentos no Brasil. In: Prêmio GTPI Jacques Bouchara de produção acadêmica voltada para o ativismo. Prêmio GTPI. Rio de Janeiro: Associação Brasileira Interdisciplinar de AIDS (ABIA), 2015. 


\section{Notas}

${ }^{1}$ O Grupo de Trabalho sobre Propriedade Intelectual (GTPI), coordenado pela Associação Brasileira Interdisciplinar de AIDS (ABIA), é um coletivo de organizações não governamentais, movimentos sociais e ativistas e pesquisadores independentes, que, desde 2003, se dedica a desenvolver estratégias no sentido de mitigar os efeitos das patentes farmacêuticas sobre políticas de acesso a medicamentos. Uma das linhas mais importantes do trabalho do GTPI é a produção de materiais, estudos e dados sobre o impacto das patentes na garantia do direito à saúde.

${ }^{2}$ Para mais informaçôes, ver: <http://www.rebrip.org.br/>.

${ }^{3}$ Paralelamente à oposiçáo à citada patente do tenofovir, o GTPI protocolou, no mesmo dia, outra monografia de oposição contra o pedido de patente do antirretroviral lopinavir+ritonavir.

${ }^{4}$ Estudos mostram que é comum, no campo farmacêutico, diversos pedidos de patentes referentes a apenas um medicamento. Esses pedidos de patentes não são dotados de inovações genuínas, mas de pequenas modificaçôes, que geram inúmeros outros pedidos. A essa estratégia, chamamos de evergreening. Com essa técnica, as companhias farmacêuticas transnacionais buscam criar um "escudo" de patentes e perpetuar seus monopólios (VILLARDI, 2012).

5 Patentes divisionais são pedidos de patentes oriundos de um mesmo pedido original. Muitas vezes, o próprio examinador solicita ao depositante que divida um pedido em dois ou três pelo fato de que as tecnologias para as quais o depositante busca o monopólio náo devem ser agrupadas no mesmo pedido. No entanto, é comum (VILLARDI, 2012) que empresas farmacêuticas lancem máo do expediente de dividir pedidos para retardar o exame ou mesmo criar um "cluster" de patentes para dificultar a entrada de medicamentos genéricos no mercado.

${ }^{6}$ Por se tratar de tema extenso e complexo, não trataremos das mudanças regulatórias e disputas políticas e jurídicas envolvendo a Anuência Prévia da Anvisa. Para mais sobre o tema, ver: GTPI (2016). 


\section{Abstract}

Activism, public policies and access to

medicines: the use of patent oppositions by

civil society organizations

This article brings the issue of access to ARV drugs and the construction of the struggles agenda of the Aids social movement regarding the tenofovir case as well as its prodrugs and the combination with emtricitabine. The article discusses which strategies the HIV movement used to avoid the patenting of such drugs, using the monographic method and the author's inside position to conduct this analysis.

> Keywords: access to medicines; AIDS social movement; tenofovir; patents; patent oppositions. 